Yapıcı H. / Sosyal Bilimler Araştırmaları Dergisi. I, (2012): 181-189

\title{
93 Harbi Sonrasında Yaşanan Göçler ve Neticeleri
}

Hakkı YAPICI ${ }^{1}$

\section{Özet}

93 harbi sonrası yaşanan elemli olaylardan biri de göçlerdir. Osmanlı ordularının Ruslar karşısında her iki cephede aldığı yenilgi Anadolu dışında yaşayan Osmanlı vatandaşlarını derinden etkilemişti. Savaş sonrası Kafkaslardan ve Balkanlardan, başta Anadolu olmak üzere, farklı coğrafi bölgelere hüzünlü ve meşakkatli göçler olmuştu. Göçe maruz kalan insanların bir yandan göçün verdiği sıkıntılara göğüs gererken diğer yandan Rus ordularının her türlü insanlık dışı hareketlerine hedef olmaları hafızalardan silinmeyecek derin izler bırakmıştır. Osmanlı Hükümeti, bu göçmenleri Anadolu'nun farklı bölgelerine iskân ettirerek bu insanların yaralarını sarmaya çalışmıştır.

Anahtar Kelimeler: 93 harbi, Osmanlı, Anadolu, Göç, Kafkas.

\section{After 93 The Migration And The Consequences Of Warfare}

\section{Abstract}

One of the most dramatic events in the post-93war is immigration. The defeats of thr Otoman armies against the Russians on both fronts have deeply influenced the Ottoman citizens living outside of Anatolia. After the war, the Caucasus and the Balkans, Anatolia, particularly in different geographic regions had been sad and arduous migrations. On the one hand while people exposed to migration can front all kinds of problem related to migration, on the other hand the fact that they were butt of all kinds of illegal activities of the Russian armies left deep and unforgettable traces in the minds.The Ottoman Government settled these immigrants in different regions of Anatolia, these people tried to heal the wounds.

Key Words: 93 war, Ottaman, Anatolia, Immigration, The Caucasian

\section{GİRIŞ}

Tarihimizde 93 Harbi olarak bilinen 1877-1878 Osmanlı-Rus Savaşı hem Rumeli'de hem de Doğu'da iki ayrı cephede cereyan etmiş, Türk

${ }^{1}$ Dr. Hakkı Yapıcı, Atatürk Üniversitesi Sosyal Bilimler Enstitüsü Yakınçağ Anabilim Dal1,hyapici25@hotmail.com 
Ordusunun ezeli düşmanı olan Rusya ile tek başına yaptığı son büyük savunma savaşıdır. Savaşın neticeleri sadece Osmanlı İmparatorluğu'nu değil, Avrupa'nın büyük devletlerini de oldukça etkilemiştir. Rusya'nın, 1853-1856 Kırım Savaşı'nın intikamını almak için yaptığı bu muharebe, Osmanlı Devleti'nin çok önemli kayıplar vermesine neden olmuştur. Savaşın sonunda imzalanan Berlin Antlaşması da açıç̧a göstermiştir ki, bu tarihten sonra Osmanlı Devleti, Avrupa devletleri tarafından yalnız bırakılarak, kendi kaderine terk edilmiştir. İngiltere, Osmanlı İmparatorluğu'nun toprak bütünlüğünü koruma politikasını bir tarafa bırakarak, sömürgelerini koruma adına Rus tehlikesini perdelemek için Kıbrıs Adası'na çıkmayı başarmıştır.

$\mathrm{Bu}$ muharebe sonrası gerek Anadolu'da gerekse Rumeli'de pek çok Osmanlı şehri tahrip olmuş, bölge halkı üzerinde savaşın izleri uzun yıllar etkisini sürdürmüştür. Rumeli'den bin bir sıkıntı içinde büyük göçler cereyan etmiştir. J. McCarthy, 93 Osmanlı-Rus harbi sonrası göç etmek zorunda kalan muhacir miktarını 1.253.500 kişi olarak gösterir. ${ }^{2}$ Bu konuyla alakalı eseri bulunan Nedim İpek ise savaş sonrası değişik sebeplerden ötürü yurtlarını terk ederek, göç etmek zorunda kalan muhacir sayısını 1.230 .000 olarak vermektedir. $^{3}$

Osmanl1-Rus Harbi'ndeki en önemli problemlerden biri yığınlar halindeki muhacirlerin kaçmak için demiryolunu kullanmak zorunda kalmalarıydı. Muhacirler cepheye asker ve malzeme taşımada kullanılacak tren vagonlarını can havliyle doldurarak, askerin lojistik destek almasını da engellemişlerdi. Hatta Süleyman Paşa'nın emriyle yaralı askerleri ve askerî malzemeyi taşımak için ayrılan trenler bile muhacirler tarafından ele

${ }^{2}$ J. McCarthy, Ölüm ve Sürgün, (Çev: Bilge Umar), İnkılap Yayınevi, İstanbul 1998, s. 105.

${ }^{3}$ Nedim İpek, Rumeli'den Anadolu'ya Türk Göçleri, Türk Tarih Kurumu Yayınları, Ankara, 1994, s. 174. 
geçirilmişti. ${ }^{4}$ Sadrazam Edhem Paşa'dan Tatarcık'ta bulunan Süleyman Paşa'ya 13 Ocak 1878 tarihinde gönderilen telgrafta; Edirne ve Filibe'de yerli ve muhacirlerden 15.000 kadar ahalinin çoluk çocuklarıyla beraber istasyonda karlar üstünde yatarak çaresizce binebilecekleri vagonları bekledikleri bildirilmişti. Edhem Paşa, aynı gün Edirne Valisi Cemil Paşa'ya da şu telgrafı çekmişti: "Telgrafnameleri alındl. Filibe'de vagonları bekleyen istasyonda kalmış oldukları beyan olunan ahalinin nakli için vagonların iki defa daha işletilmekte bir mahsur yok ise kumpanyaya emir verilerek ahali-i merkumenin nakledilmesi Süleyman Paşa'ya yazılmıştır. Bundan dolayı ahalinin nakil sebeplerinin derhal bildirilmesinin lüzumu bildirildi. Cemil Paşa, bu telgrafi aynen Süleyman Paşa'ya ileterek, "artık ne yapılmak lazım ise ferman buyrulmasına hazırım" demişti. ${ }^{5}$

Bu savaşta Ruslar, Türkleri önce Rusya'ya tehcir etmek istemişler ama daha sonra bundan vazgeçerek topluca yok etme planını uygulama yolunu seçmişlerdi. Rusların sivil halkı kıyımdan geçirmeye girişmelerinin ardında yatan başlıca gaye, Türk köylüleri arasında dehşet salarak yurtlarından kaçmalarını sağlamaktı. Bu planı uygulamak için en uygun göç Don-Volga Kazaklarıydı. Kazaklar yüzyıllardan beri özellikle sivil halka karşı uyguladıkları vahşetle kirli savaşlar yapmanın ustasıydılar. Onların yaklaştığı söylentisinin çıkması, bile tam onların tasarladığı gibi, Türk muhacirlerin yollara dökülmesine yetiyordu. Rusların ve Bulgarların bu savaşta uyguladıkları mezalimin boyutları korkunçtu. Savaşı izlemek üzere Şumnu'da bulunan Manchester Guardin, Kölnische Zeitung, Journal des Debats, morning Post, Pester Lloyd, Wiener Tageblatt, Telegraph vs. Avrupa gazetelerin muhabirleri 20 Temmuz'da ortak imzalarıyla yayınladıkları bir duyuruda Razgat ve Şumnu'da savaştan ve kıyımdan kaçmaya çalışan çocuk, yaşlı ve kadınların

${ }^{4}$ H. Yıldırım Ağanoğlu, Osmanlı'dan Cumhuriyet'e Balkanların Makûs Talihi (Göc)), İz Yayıc1lık, İstanbul, 2001, s. 33-34. 
insanlık dışı bir şekilde Ruslar tarafından mızrak ve kılıçlarla yaraladıklarını kendi gözleriyle gördüklerini belirtmekteydiler. Muhacirlerin katliamdan kurtarmaya çalışırken karşılaştıkları en önemli problemlerden biri de soğuk ve açlıktı. Birçoğu bu yüzden yollarda ölmüşlerdir. ${ }^{6}$

Rusların Tuna'yı geçip de İstanbul önlerine kadar vardıkları güne kadar 600.000 Türk, yerini yurdunu bırakarak göç etmek zorunda kalmıştı. Bu göçmenlerden 100.000 kadarının Anadolu'ya geçtiği, 150.000 göçmenin İstanbul'a ve 150.000 göçmenin de Rodop Dağlarına sığındıkları bilinmektedir. Kalanı da Rumeli'nin muhtelif yerlerine dağılmıştı. Anadolu'ya geçirilen göçmenler, Orta ve Batı Anadolu vilayetlerine yerleştirilmişlerdi. Selanik ve Kosova vilayetlerine sığınan 300.000 göçmenle, Şumnu çevresinde toplanan 200.000 göçmen bunlara dâhil edilirse bir milyon insanın yerinden oynadığını görürüz ki, halk arasında buna "Koca Bozgun" denmiştir."

Rumeli'de 93 Harbi sonrasında Müslümanlar, Bulgaristan ve Sirbistan elinde kalan bölgelerden ayrılarak Kosova, Manastır, Selanik gibi vilayetlere de yerleştirilmişler, İmparatorluğun diğer bölgelerindeki Bulgarların bir kısmı da Bulgaristan ve Doğu Rumeli’ye göçmüştü. ${ }^{8}$ Ayrıca Kafkaslardan gelen bazı muhacirler $^{9}$ de Balkanlara, özellikle Bulgaristan sinır boylarına, yerleştirilmişti. ${ }^{10}$

${ }^{5}$ Bilâl N. Şimşir, Turkıs Emıgratıons From The Balkans, C.I, A. Turkısh Exodus, Printed At Turkısh Historical Society, Ankara, 1989, s. 269.

${ }^{6}$ Ağanoğlu, a.g.e., s. 34-35.

${ }^{7}$ Osman Keskioğlu, Bulgaristan'da Türkler, Kültür ve Turizm Bakanlığı Yayınları, Ankara 1985, s. 13.

${ }^{8}$ Rumeli topraklarından başka bölgelere yapılan göçlerle ilgili daha detaylı bilgiler için bkz. Kemal Beydilli, "Balkanlar'da Dönüm Noktası 93 Bozgunu ve Sonrası", Berlin Antlaşması'ndan Günümüze Balkanlar, (Yayına Hazırlayan: Mustafa Bereketli), Rumeli Vakfı Kültür Yayınları, İstanbul 1999, s. 33.

${ }^{9}$ Savaş sonrası Rusya topraklarından hicret edip henüz iskânları icrâ olunmayan 300 hane Kafkasya muhacirleri Anadolu'da değişik yerlere yerleştirilmişlerdi. BOA.(Mektubî Kalemi) MKT, nr.1333/95 (9 Cemaziyel-evvel 1297/12 Kasım 1880 tarihli Eyüp Hayri Paşa'dan gelen telgraf).

${ }^{10}$ Ağanoğlu, a.g.e., s. 39. 
93 Harbi Kafkas bölgesinden Anadolu'ya yapılan göçe yeni bir ivme kazandırmıştır. Bu savaşta Kafkasya coğrafyasında yaşayan Türkler, Çerkezler, Çeçenler, Abazalar, Dağıstanlılar ve Acara çevresinde bulunan Müslüman Gürcüler aktif olarak Osmanlı Devleti’nin yanında savaşa katılmışlardı. Savaş Osmanlı aleyhine sonuçlanıp Kafkaslar yine Rusya'nın hâkimiyetinde kalınca Müslüman Kafkas toplumları da bunun acı neticesi ile karşılaşmışlardır. ${ }^{11}$

3 Haziran 1888 tarihinde, Trabzon vilayeti valiliğinden Dâhiliye Nezareti'ne gönderilen telgrafta, Artvin-Murgul ahalisinden 445 muhacirin İzmit ve Bursa cihetine iskân olunmaları için Dersaadet'ten vapur gönderilmesi istenmişti. 6 Haziran tarihinde, Trabzon valiliğinin telgrafına hükümetten olumlu cevap verilmiş, Batum ve Artvin muhacirleri Anadolu'nun muhtelif yerlerine iskân edilmişlerdir. ${ }^{12}$ Batum dahilinde Livane kazasından 1.300 hane hicret etmek istemişlerse de mahalli hükümet tarafından bu talebleri kabul edilmemişti. 1886 tarihinde Batum muhacirlerinden 600 hane halkın istidaları üzerine bunlardan 200 hanesinin Erzurum'a, 400 hanesinin İzmir'de iskânlarına karar verilmiş ise de hicretleri hakkında Rusya hükümeti tarafından verilen sürenin dolmasından ötürü bu istekleri gerçekleşmemiştir. Ancak Batum muhacirlerinin göç etme arzuları devam ettiği için Osmanlı hükümeti, bu isteği dikkate alarak, muhacirlerin uygun bölgelere iskânlarını yapmıştır. ${ }^{13} 1887$ yılında da göçler devam etmiş, Batum'dan birkaç bin muhacir Samsun iskelesine gelerek değişik bölgelere nakledilmişlerdi. ${ }^{14}$

Savaş sonrası hicret etmek zorunda kalan muhacirler gerek göç esnasında ve gerekse sonraki yaşamlarında oldukça meşakkatli günler yaşamışlardı. 5 Aralık 1879 tarihli bir belgede muhacirlerin trajedisi şöyle

\footnotetext{
${ }^{11}$ Muammer Demirel," Artvin ve Batum Göçmenleri (1877-1878 Osmanlı-Rus Savaşı'ndan Sonra)", Atatürk Üniversitesi Türkiyat Araştırmaları Enstitüsü Dergisi, sayı: 40, Erzurum, 2009, s. 317.

${ }^{12}$ BOA. DH. MKT, nr. 1331/ 84.

${ }^{13}$ BOA. DH. MKT, nr. 1337/ 10.

${ }^{14}$ BOA. DH. MKT, nr. 1442/ 69.
} 
anlat1lir:"Dersa'adet'te mevcut olan ve Rumeli'ye gidenlerden avdet eden ve Anadolu'nun mevaki-i muhtelifesine gönderilenlerden memleketlerine azimet niyetiyle vürud eden muhacirîn fevkalade acınacak bir hal-i perişanî ve sefâlette bulunmaktadırlar ve bunlar geçen ve evvelki senelerde olduğu gibi ne devletçe ve ne de ahalice muâvenet olunmaylp kable'- muhârebe Dersa 'adet'te Rumeli ahalisinden tese'ül eder bir şahs görülmek şöyle dursun bayağı dairelerde hizmetkârlı edenler bile madud iken bugünki gün muhacirîn-i merkûmeden birçok kadın ve kızlar sokaklarda âr-ı suâli ihtiyar etmektedirler. Bunların duçar oldukları hâl-i felaket cümleyi dilhûn etmekte ve haklarında hükümet-i seniyyenin şefkat ve merhameti ve mümkün olabilecek suretle muâveneti temenni kılınmaktadır. Muhacirîn-i merkûme işlerine bakmakta olan encümen-i âli riyâset-i sâniyesinde bulunan zat evsâf-l memduha-i gayret ve hamiyetle mevsuf ise de gerek sinnen ve gerek vîcûden bu misüllü ağır işlerle uğraşmăga muktedir olmadı̆̆ından ve umûm-ı muhacirînin mümkün mertebe ıslâh-ı ahvâlleri nezd-i meal-i vefd-i cenab-ı mülükânede matlub ve mültezim bulunduğundan yine o hey'et-i suret-i resmiyyede baki kalmak ve ara sira icraat-ı vâkiadan oraya malumat verilmek üzere idare komisyonuna bir iki nefer aza ilavesiyle riyâsetine genç ve gayretli ve ale'ddevam muhacirînin ıslah-ı ahvalleri ve haklarında lâzım gelen muavenetin icrası esbabını istihsale çalışacak bir zatın tayini icabı halde olup Bosna valisi sabık Mazhar Paşa'dan şu yolda hareket kaviyyen me'mul bulunduğundan ânın veyahut o sifatta diğer birinin hizmet-i mezkûreye tayini ve Anadolu'ya gönderilen ve Selanik ve Kosova ve Trabzon taraflarinda bulunan muhacirînin halleri dahi burada bulunanlardan farklı olmayı anların dahi günbegün perişanî-i halleri artmakta ve içlerinde vefeyât çoğalmakta olduğundan bunların istifsâr-ı ahvâlleri ve ne miktarının suret-i kat’iyyede yerleştürülüp ne kadarının hâl-i müsâferette bulundukları hakkında riyaset-i müşârünileyhânın zikr olunan vilayetlerle doğrudan doğruya icrâ-yı muhaberâta me'zun edilmesi suretleri münasip gibi 
vârid-i hatır-ı kasır olur ise de kâtıbe-i ahvalde emr ü ferman hazret-i veliyyül emrindir." 15

O günün şartlarında muhacirler vatanlarını bırakarak bin bir zahmetle yolculuk etmişlerdir. ${ }^{16}$ Göçmenleri yollarda açlık, sefalet, hastalık ve dolayısıyla ölüm beklemekteydi. Bulaşıcı hastalıklar muhacirler esnasında kol gezmekte olduğundan, göçmenler, gittikleri yerlere de hastalık yaymışlardır. Bazı iskân yerlerinin tarıma elverişli olmamasından dolayı bir kısım göçmen kafileleri aç ve sefil kalarak perişan olmuşlardır. ${ }^{17}$

Umumi servet açısından gerek savaş sonrası Balkan ve Kafkas bölgelerinden Anadolu'ya sığınmak mecburiyetinde bırakılan göçmen Osmanlı teb'ası gerek yerli Anadolu halkı ve gerekse genel devlet ekonomisi açısından uğranılan zarar ve ziyâna gelince, savaşın neden olduğu ekonomik çöküntü tüm çıplaklığı ile karşımızdadır.

Şöyle ki; 16.000.000 liralık kâğıt para kıymetten düşerek halkın elinde kalmıştır. Bunun büyük kısmı mecburî bağış şeklinde hükümete iade edilip yakılmış ve dört yüz kuruşluk kâğıt para, bir Osmanlı yüzlük altınına denk sayılarak halktan, devlet dairelerinde alacağı olanların alacakları, o şekilde ödenmiştir. Bu hesaba göre umumi servetten 16.000.000 lira eksildiği gibi, kâğıt paradaki bu değer kaybı, bakır ve gümüss paralara da sirayet ettiğinden, 8.700.000 liralık bakır para, itibârî kıymetince altına nispeten yüzde doksan zararla tedavülden çekilmiştir. "Metelik" denilen gümüş paraların itibârî

\footnotetext{
${ }^{15}$ BOA. Y.E.E. nr. $44 / 124$.

${ }^{16}$ Bulgaristan Müslümanlarının büyük bir sefalet içinde yerlerini yurtlarını terk edişlerinde ise pek çok insan hayatını kaybetmiş, sayısız İslam hanesi kapanmıştır. Bulgaristan Prensliği’nin kurulmasından sonra elinde parası, mülkü olan nice servet sahibi Müslüman, antlaşma ile belirlenen haklardan istifade edemeyerek, menkul malları göç esnasında mahvolduğu gibi, gayrimenkul malları da ya basit bir sebeple müsadere edildi veya türlü hileli yollarla yok pahasına sattırılmak mecburiyetinde bırakılarak mağdur ve perişan edildi. Bu yüzden, birkaç yüz seneden beri babadan oğula servet sahibi olan köklü Müslüman aileleri bir anda fakr u zaruret içine düşerek zelil oldular. (Mahmut Celâleddin Paşa, Mir'ât-ı Hakîkat, Cilt: I-II-III, Berekât Yayınları, İstanbul 1983, s. 683).
} 
kıymeti yarı yarıya düşürüldüğünden, ellerinde bu şekilde nakit para bulunanlar bir defada servetlerinin yarısını kaybetmişlerdir. Kısacası kâğıt ve madeni paraların değer kaybetmesi ve kıymetten düşmesi yüzünden millet 30.000.000 lira civarında zarara uğramıştır. ${ }^{18}$

Netice olarak yakın tarihimize damgasını vuran 93 harbi olarak da bilinen, bu Osmanlı-Rus muharebesinin ağır neticeleri arasında göçün olumsuz yankılarını da görmekteyiz. Yurtlarını ve sahip oldukları her şeyi bırakmak mecburiyetinde olan muhacirler çaresiz olarak Anadolu'ya sığınmak zorunda kaldılar. Muhacirlerin istihdamı ve ihtiyaçlarının karşılanması, savaşı kaybetmiş mali durumu zaten kötü olan Osmanlı Devletine oldukça büyük külfet getirmiştir.

\section{Kaynakça:}

1-Başbakanlık Osmanlı Arşivi (BOA), Dâhiliye Mektubî Kalemi (DH. MKT), nr. $1331 / 84$. 2-BOA. DH. MKT, nr. 1337/ 10.

3- BOA. DH. MKT, nr. 1442/ 69.

4- BOA. Mektubî Kalemi (MKT), nr.1333/95

5- BOA. Yıldız Esas Evrak (Y.E.E). nr. 44/124.

6-Ağanoğlu, H. Yıldırım (2001) Osmanlı'dan Cumhuriyet'e Balkanların Makûs Talihi (Göç), İstanbul, İz Yayıncılık.

7-Beydilli, Kemal (1999) "Balkanlar'da Dönüm Noktası 93 Bozgunu ve Sonrası", Berlin Antlaşması'ndan Günümüze Balkanlar, (Yayına Hazırlayan: Mustafa Bereketli), İstanbul, Rumeli Vakfı Kültür Yayınları.

8- Carthy, J. Mc,, (1998) Ölüm ve Sürgün, (Çev: Bilge Umar), İstanbul, İnkılap Yayınları.

9-Demirel, Muammer, (2009)"Artvin ve Batum Göçmenleri (1877-1878 Osmanl1-Rus Savaşı'ndan Sonra)", Atatürk Üniversitesi Türkiyat Araştırmaları Enstitüsü Dergisi, say1: 40, Erzurum.

\footnotetext{
${ }^{17}$ Demirel, a.g.m., s. 339 .

${ }^{18}$ Mahmut Celâleddin Paşa, a.g.e., s. 683.
} 
Yapıcı H. / Sosyal Bilimler Araştırmaları Dergisi. I, (2012): 181-189

10- Keskioğlu, Osman (1985) Bulgaristan'da Türkler, Ankara, Kültür ve Turizm Bakanlığı Yayınları.

11-Mahmut Celâleddin Paşa, (1983) Mir'ât-ı Hakîkat, Cilt: I-II-III, İstanbul, Berekât Yayınları.

12- İpek, Nedim (1994) Rumeli'den Anadolu'ya Türk Göçleri, Ankara, Türk Tarih Kurumu Yayınları.

13- Şimşir, Bilâl N., (1989)Turkıs Emıgratıons From The Balkans, C. I, A. Turkısh Exodus, Ankara, Printed At Turkısh Historical Society. 